\title{
The Composition of Innovative Psychological Structure of College Students and Suggestions for Innovative Education
}

\author{
Wu Quanhui ${ }^{1}$, Liu Guibao ${ }^{2, *}$ \\ ${ }^{1}$ College of Psychology and Educational Science, Zaozhuang University, Zaozhuang, Shandong Province, China \\ ${ }^{2}$ College of Psychology and Educational Science, Zaozhuang University, Zaozhuang, Shandong Province, China \\ *Corresponding author.Email: liufine1122@163.com
}

\begin{abstract}
In the innovation ability system, besides explicit indicators such as knowledge and experience, psychological quality also occupies an important position. This article combs the current research status of college students' innovative psychology, explores the key psychological factors that affect college students' innovative ability, constructs a structural system of college students' innovative psychology, and makes suggestions for college innovation education reform.
\end{abstract}

Keywords: college students, innovative psychological structure, innovative education

\section{INTRODUCTION}

The core of national strength is science and technology, the key to science and technology is talents, and the foundation of talents is education. Since the 19th National Congress of the Communist Party of China, the Party Central Committee with Comrade Xi Jinping has attached great importance to the development of talent teams. Series of important instructions. General Secretary Xi Jinping clearly pointed out: "Innovation is the first driving force to lead development. To grasp innovation is to grasp development, and to seek innovation is to seek the future." In the context of socialist construction and the transformation of new and old kinetic energy, education must adapt to the development of the times. It is the mission and responsibility of education to cultivate more and better innovative talents and provide intellectual support for the country's development and national rejuvenation. It is the task of the times that my country's higher education must undertake in the new era to cultivate the innovative ability of college students.

\section{STATUS QUO OF RESEARCH ON UNIVERSITY STUDENTS' INNOVATIVE PSYCHOLOGY}

\subsection{Foreign Research On Innovative Psychology}

In the innovation ability system, in addition to explicit indicators such as knowledge and experience, psychological quality also occupies an important position. In foreign countries, European and American countries have noticed the influence of psychological quality on people's ability to innovate (creative) earlier, and have produced fruitful research results. Many wellknown psychologists have participated in it and have a profound impact in the fields of education and management. For example, in 1926, American psychologist Wallers proposed four stages of creation, including preparation, incubation, clarity, and verification; in 1945, German psychologist Wittheimer analyzed the specific process of innovative thinking with the perspective of Gestalt psychology; In 1950, American psychologist Guilford pointed out the lack of research on innovative psychology in American education and psychology at that time, which attracted the attention of national decision-makers and greatly promoted the development of innovative psychology, making it a sub-discipline of psychology. . In 1976, 
American psychologist Erici published "The Magical Synthesis of Creativity", a comprehensive and systematic monograph that introduced the psychological structure that affects people's ability to innovate and create, with far-reaching influence. In 2013, the wellknown positive psychologist Hiszant Mihai published "Creativity: Flow and Innovation Psychology", becoming a master of innovation science. In recent years, developed countries in Europe and the United States have paid special attention to the impact of psychological quality on people's innovation ability. Not only universities, but many companies have also actively introduced innovative psychological training courses to improve their innovation capabilities and seize the talent pool.

\subsection{Domestic Research}

Domestic attention to this aspect started late, but with the national development's call for innovative talents and the reform of the university's talent training model, it has developed rapidly, and a large number of theoretical results have emerged. For example, Professor Lin Chongde of Beijing Normal University published "Education and Development: A Concurrent Study of the Psychological Integration of Innovative Talents" in 2013, which explored the psychological characteristics of innovative talents and put forward constructive opinions on how to do a good job in innovative psychological education. Liu Linlin studied the psychological motivation factors of innovation in the article "Research on Innovation Ability Based on College Students' Innovative Psychological Motivation". Cui Lizhong analyzed the psychological structure and laws affecting innovation in the article "The Psychological Essence of Independent Innovation"[1]. These studies are mainly concentrated in three directions: one is the role and value of psychological quality factors in the macroscopic deduction of innovation ability system; the other is to start with different psychological factors (such as motivation and thinking) and analyze their impact on innovation ability; The third is to explore how to cultivate students' innovative psychological quality in teaching practice.

\subsection{Research On Innovative Psychology Under The Information Environment}

With the development of information technology, education informatization and the corresponding informatization learning environment are becoming more and more mature. Information-based learning environment is a learning place or activity space that can perceive learning situations, identify learner characteristics, provide appropriate learning resources and convenient interactive tools, automatically record learning processes and evaluate learning results, so as to promote learners to learn effectively. In the information- based learning environment, large-capacity and intelligent learning resources require learners to have the corresponding demand management ability, knowledge construction ability and psychological resilience, otherwise, they will be extremely lost in the network. In such a situation, the role of the learner's mental state and mental energy is more significant, and it is easier to be identified and measured. Therefore, in the smart learning environment, studying the innovative psychological structure and innovative psychological mechanism of learners has obvious technical and method advantages[2].

Based on the aforementioned research results, this research makes full use of the advantages of the information-based learning environment in the information age, combined with the psychological characteristics of college students in the new era, and analyzes the digital learning data of 3 classes of innovation and entrepreneurship courses and the learning data of 3 applied courses. Combining the basic knowledge of psychology, it analyzes and combs the composition structure and function law of innovative psychological quality, and proposes curriculum and teaching reform suggestions for the cultivation of innovative psychology based on this, so as to promote the cultivation of innovative talents in colleges and universities.

\section{INNOVATIVE PSYCHOLOGICAL STRUCTURE OF COLLEGE STUDENTS}

At present, all colleges and universities spend a lot of hours and energy on teaching students the knowledge, skills, methods and even laws and regulations needed for innovation. However, insufficient attention has been paid to the psychological factors of the students themselves. Combining interviews with students, using behavioral analysis to analyze students' course learning data, and comparing the innovative expressions of the course ending works (referring to Torrance's Creativity Test and Gilford's Divergent Thinking Test, according to the breadth, depth, Fluency, flexibility and uniqueness evaluation works), to conduct research on innovative psychological structure. Research has found that if people's ability to innovate is regarded as an iceberg, in addition to explicit factors such as knowledge, experience, and skills, the underwater part composed of psychological qualities such as motivation and personality is also the core element of innovative ability[3].

\subsection{Competence, Attitude And Values}

In the mental structure, the closest to the surface (dominant) and the easiest to observe are abilities, attitudes and values. Ability is the comprehensive quality embodied in the completion of a goal or task. 
Here we regard it as the integration effect of all psychological factors and place it at the top of the psychological factors. Attitudes and values are key aspects of teaching goals, and they often form one dimension of three-dimensional teaching goals together with emotions. In the research, most of the students' learning data (such as the novelty of participating in the discussion of the problem) has a clear positive correlation with the learning results. Very few abnormalities are found through interviews and are affected by attitudes, that is, students' attitudes towards homework or work The degree of attention. The degree of importance is affected by the determination of values. Therefore, ability is a comprehensive factor in innovation ability, and attitude is the subjective psychological structure that affects the level of ability. Values, as a relatively stable psychological element, constitute the psychological power of attitude.

\subsection{Imagination}

Imagination is the core of the psychological structure of innovation, and the level of innovation (or creation) is directly affected by imagination. Piaget's psychologists have done a lot of research on this point. What needs to be emphasized is that in this research, we believe that imagination is the "internal" form of innovative ability, and when realized in social reality, it becomes innovative ability.

\subsection{Emotions And Self-awareness}

Emotions and self-awareness are in the middle of the structure, which are the elements of psychological introspection, which are crucial to the practical process of college students turning imagination into innovative ability. Bad emotions and incorrect self-awareness will limit the development of college students' innovative ability. The lower level of interpersonal communication is a social support factor. Although it is not found to be clearly related to innovation ability in this study, considering that innovation ability will eventually move toward social reality, the formation of entrepreneurial ability will inevitably require interpersonal support, so it is placed on the 7th layer. . Many of the weaknesses that college students present in the process of innovation are lack of correct self-awareness and difficulty in emotional management, such as high eyesight, low hands, lack of self-confidence, and so on. In general, too high self-awareness often leads to lack of rational thinking and in-depth research, so that excellent innovative thinking lacks continuous nutrition and withers; too low self-awareness often results in a lack of self-confidence and courage to innovate, and can't believe that they can To do so, let innovative thinking and creative results lack sunshine and wither silently.

\subsection{Needs And Motivations}

At the bottom are personality, motivation and needs. They all belong to the category of generalized personality psychology. In particular, motivation and needs have a profound and significant impact on innovation ability. There are many students who lack innovation motivation and thus lack of learning enthusiasm, and lack of motivation has become one of the bottlenecks that restrict the development of college students' innovation ability. Moreover, according to Maslow's level of needs and Marx's development thoughts, the need for the level of motivation to achieve the unity of the socialization and individualization of education is a key node for innovative education reform[4].

In addition, whether there are other psychological factors is limited by the research conditions, and cannot be studied in depth. Judging from the existing structural models of innovation capability, whether it is the SEM based innovation capability model or the multi-level fuzzy comprehensive evaluation model, the lower-level capabilities such as knowledge learning ability, imagination ability, technical ability and information processing ability are regarded as innovation ability. important parts of. In order to achieve personalized development and to cultivate innovation ability, we must pay attention to the psychological growth of students.

\section{SUGGESTIONS FOR DEVELOPMENT OF COLLEGE STUDENTS' INNOVATIVE EDUCATION BASED ON INNOVATIVE PSYCHOLOGICAL STRUCTURE}

The core quality of innovation ability should be the psychological quality of innovation, including the 10 aspects of motivation, needs, ability, and attitude analyzed above. Based on this, we propose the following innovative education development suggestions:

\subsection{Pay Attention To The Role Of Psychological Factors In The Cultivation Of Innovative Ability}

Colleges and universities should fully recognize and attach importance to the status and role of psychological structure in the innovation ability system. Innovation is the need of social development, but it is based on individual psychological needs. Only by paying full attention to and in-depth research on the innovative psychological structure of college students, clarifying its structure, mechanism and psychological principles, and carrying out targeted cultivation, can it stimulate college students' innovative motivation, form a good innovative mentality, develop their abilities, and realize the 
cultivation of innovative talents[5].

\subsection{Increase The Content Of Psychological Factors In Innovative Courses}

In the current innovation and entrepreneurship courses in colleges and universities, the attention to student psychology is obviously insufficient, and there is a lack of systematic theoretical combing and practical accumulation, which leads to the waste of the innovative theories, innovative skills, and innovative methods taught by the students because the psychological quality of the students themselves is not up to the standard. We suggest that in the innovation curriculum, the content of innovative psychological cultivation should be appropriately increased in a planned and step-by-step manner, so as to fundamentally cultivate students' innovative ability.

\subsection{Make Full Use Of The Informational Teaching Environment To Cultivate Innovative Psychology}

Today, with the rapid development of educational information, informational learning pays more attention to learners' psychology and behavior, and the same applies to the cultivation of innovative ability. According to the students' innovative psychological structure and mechanism, the targeted training of students' innovative ability can make up for the lack of current innovation and entrepreneurship education and improve the innovative ability of college students. Relying on the information environment, in-depth study of which aspects of psychological quality have a clear and specific impact on innovation ability, which psychological factors are necessary for students to innovate or start a business, how to scientifically cultivate and stimulate these psychological qualities, It is of great value to improve the current college students' innovative education and build a modern learning environment for innovative education.

\section{CONCLUSION}

At present, there is still a gap about innovation and entrepreneurship capabilities compared with developed countries, and the effectiveness of innovative capacity training is far from meeting the needs of national development. Although most colleges and universities regard innovation (entrepreneurship) education as an important course, according to the statistics of the employment situation of Chinese college students in 2016 by Michaels, the proportion of college students' entrepreneurship has risen from $2.0 \%$ in the class of 2012 to $3.0 \%$ in the class of 2016; college students Only $6.1 \%$ are willing to start a business on their own, while less than $1 \%$ of college graduates who have embarked on an entrepreneurial path and have developed smoothly (the enterprise is still alive after three years) (data source: Max University Employment Report: 2017). Although entrepreneurship and innovation are not necessarily linked, excellent innovation ability is the core factor that promotes the development of entrepreneurship.

This thesis explores the key psychological factors that affect the cultivation of college students' innovative ability, builds a structural system of college students' innovative psychology, and puts forward three suggestions for innovative education reforms in colleges and universities, hoping to attract more peers' attention and conduct in-depth research on this. To better cultivate the innovative psychological quality of college students and improve the level of innovative ability.

\section{AUTHORS' CONTRIBUTIONS}

Constructed a structural system of college students' innovative psychology, and put forward suggestions on the reform of college's innovative education.

\section{ACKNOWLEDGMENTS}

This article is the research result of Shandong Province's 2018 teaching reform research project "Undergraduates' Innovative Psychological Structure Exploration and Innovative Quality Cultivation Research" (10904201804).

\section{REFERENCES}

[1] Liu Guibao. Research on the Development of the Form and Structure of Chinese Universities [M]. Zhengzhou University Press. 2017.

[2] Yingfang Zhao, Guibao Liu. How Do Teachers Face Educational Changes in Artificial Intelligence Era[A]. Wuhan Zhicheng Times Cultural Development Co., Ltd. Proceedings of 2018 International Workshop on Education Reform and Social Sciences (ERSS 2018) [C].

[3] Lou Liandi, Pang Weiguo. The influence of knowledge base on college students' innovative thinking $[\mathrm{J}]$. Journal of East China Normal University (Educational Science Edition), 2014, 32(04): 90-98

[4] Yuan Guiren. Research on Marxist Human Theory [M], Beijing Normal University Press. 2017, 6.

[5] Qiu Jiang, Zhang Qinglin. The cognitive neural mechanism of prototype activation to induce epiphany in innovative thinking[J]. Advances in Psychological Science, 2011, 19(03): 312-317. 